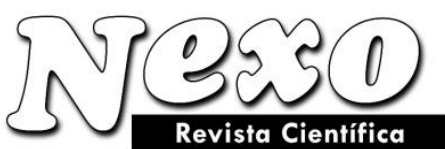

Vol. 36, No. 06, pp. 1768-1776/Diciembre 2021

\title{
Development of methodology for determining a-parameters of an asymmetric rail line
}

\section{Desarrollo de metodología para determinar parámetros a de una línea ferroviaria asimétrica}

\author{
Evgeniy M. Tarasov*, Nicolay N. Vasin, Anna E. Tarasova \\ Samara State Transport University. Samara, Russia. \\ *Corresponding author E-mail: e.tarasov@ samgups.ru
}

(recibido/received: 28-octubre-2021; aceptado/accepted: 07-diciembre-2021)

\begin{abstract}
The article considers the methodology of forming the matrix of A-parameters of a rail line, represented by a multi-pole equivalent circuit. It is shown that when using a four-pole equivalent circuit of a rail line in case of violation of the equipotentiality of the circuit, it is impossible to take into account the flow of current along bypass paths, along the earth path, and the influence of adjacent track circuits. A multi-pole equivalent circuit of a rail line is represented as a $2 \times 4$ pole, in the rail lines of which self-induction EMF sources are included, and an earth path is used as the second wire. An equivalent multi-pole of equivalent circuit is represented by two groups of poles - at the input and output of the rail line, including one common (ground). The parameters of all elements of the equivalent multi-pole circuit are presented in the form of matrices, which makes it possible to analyze the state of the rail lines when changing the primary parameters of the rail multi-pole in a wide range. Using Kirchhoff's laws and solving a system of ordinary differential equations, the A-parameters of a rail multi-pole are obtained.
\end{abstract}

Keywords: Four-pole; Kirchhoff's laws; Matrix; Multi-pole; Rail lines; System of differential equations.

\section{RESUMEN}

El artículo considera la metodología para formar la matriz de parámetros A de una línea ferroviaria, representada por un circuito equivalente multipolar. Se muestra que cuando se usa un circuito equivalente de cuatro polos de una línea ferroviaria en caso de violación de la equipotencialidad del circuito, es imposible tener en cuenta el flujo de corriente a lo largo de las rutas de derivación, a lo largo de la ruta de tierra y la influencia de circuitos de vía adyacentes. Un circuito equivalente multipolar de una línea ferroviaria se representa como un polo 2x4, en las líneas ferroviarias de las cuales se incluyen fuentes EMF de autoinducción, y se utiliza una ruta de tierra como segundo cable. Un circuito equivalente multipolar equivalente está representado por dos grupos de polos: en la entrada y salida de la línea ferroviaria, incluido uno común (tierra). Los parámetros de todos los elementos del circuito multipolar equivalente se presentan en forma de matrices, lo que permite analizar el estado de las líneas ferroviarias al cambiar los parámetros primarios del multipolar ferroviario en un amplio rango. Utilizando las leyes de Kirchhoff y resolviendo un sistema de ecuaciones diferenciales ordinarias, se obtienen los parámetros A de un carril multipolar. 
Palabras claves: Cuatro polos; Las leyes de Kirchhoff; Matriz; Multipolar; Líneas ferroviarias; Sistema de ecuaciones diferenciales.

\section{INTRODUCTION}

In the analysis and synthesis of track circuits, one of the main tasks is to determine the dependencies between the complex amplitudes of the input and output electrical parameters of RL, depending on the class of its states. With the existing methods, these dependences are determined by the state equations of four-pole rail line equivalent circuits (Bruin et al., 2017). The analysis of established and transition modes in homogeneous long lines, which include rail lines in the absence of external and mutual influences, is based on the so-called telegraph equations. The solution of these hyperbolic partial derivatives differential equations is carried out using the Dalembert method and the Fourier method.

The first method is based on the superposition of incident and reflected waves on each other and describes the physical processes in the lines well, but it is difficult to take into account the waves attenuation when implementing it. The second approach is based on the representation of the phenomena of summed standing waves, it is less "physical", but more convenient for practical calculations.

Despite the attractiveness of both methods, the analytical description of energy processes has a limited range of application, namely, it does not allow analyzing the longitudinal and transverse mutual influences of lines. When using the scheme of substitution of a long line by a four-pole, the expressions for determining the matrices of A-parameters are formed by the mode of operation, and therefore it is impossible to develop a single algorithm of solving them on a computer.

In the equipotential state of the rail line (RL) scheme, the current does not flow through the earth path, but if the equipotentiality is violated, the current begins to flow through the earth path from the source to the receiver. This feature is especially necessary to take into account when constructing intelligent train traffic control systems, when it is impossible to ensure invariance to perturbations affecting the rail line survey signal additively or parametrically (Tarasov, 2017; Tarasov et al., 2020).

To compile a mathematical model of a track circuit as a sensor of primary information, it is necessary to obtain a matrix of A-parameters of a three-wire rail line, which will allow, together with the matrices of elements of matching devices, to study the nature of spreading of the survey signal in various classes of RL states (Gao and Ma, 2021).

\section{METHODOLOGY}

Based on the specific tasks of analysis and synthesis of rail circuits-devices for monitoring the state of rail lines, their mathematical model have to meet various requirements. For example, to accurately describe the processes of establishing the dependence between the complex amplitudes of currents and voltages at the input and output of the rail line, to evaluate the energy parameters of power transmission from the source of the rail lines survey signal to the classifier of conditions, to analyze the dynamic range of changes in complex amplitudes of voltages and currents depending on change in internal parameters and external influences on the information transmission path, to have a universal equivalent circuit that allows for a comprehensive analysis of the quality of track circuits functioning in all modes. These requirements are contradictory, and it is impossible to generalize mathematical models in various states of rail lines when using four-pole substitution schemes.

In this regard, the objective function of this work is to develop a generalized multi-pole equivalent circuit for a rail line, which allows forming a matrix of A-parameters of a rail multi-pole, that considers the influence of external and internal factors, fluctuation in the parameters of the equivalent circuit components, 
as well as the mutual influence of track circuits - sensors of states of rail lines (Kravtsov, 2015; Shamanov, 2013) (Figure 1).

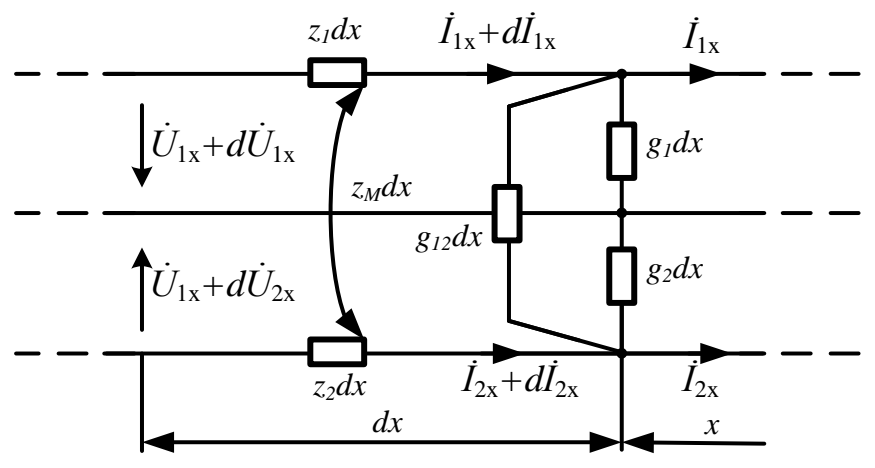

Figure 1. Scheme of a multi-pole element $d x$ of a rail line: $z_{1}, z_{2}$-the longitudinal resistances of the rails; $g_{1}, g_{2}$ - the ground conductivity of the rails; $g_{12}$ - the conductivity of the ballast and cross-sleepers; $z_{M}$ - the mutual induction resistance; $x$ - the distance from the end of the rail line; $\dot{I}_{1 x}, \dot{I}_{2 x}$ - the complex amplitudes of the currents flowing along the first and second rails; $\dot{U}_{1 x}, \dot{U}_{2 x}$ - the complex amplitudes of the stresses of the first and second rail threads relative to the ground.

When displaying the RL in the form of a multi-pole circuit, the matrix of parameters of the six-pole, presented as a special case in Figure 2, has a dimension equal to four (Volkov et al., 2005).

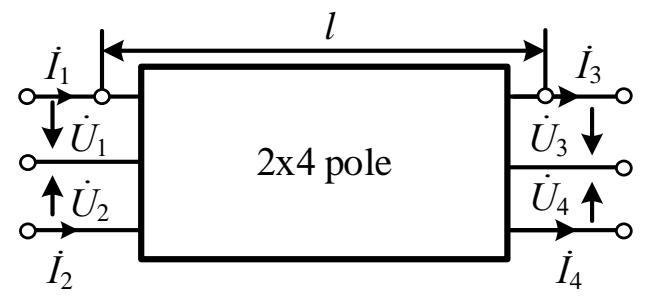

Figure 2. Equivalent circuit of the rail line in the form of a multi-pole.

If, in the particular case, we consider the currents $\dot{I}_{1}$ and $\dot{I}_{2}$ flowing in, and $\dot{I}_{3}$ and $\dot{I}_{4}$-flowing out, then the system of linear equations, with which it is possible to determine the coefficients of the matrix of $A$ parameters, has the form:

$$
\left\{\begin{array}{l}
\dot{U}_{1}=\underline{a}_{11} \dot{U}_{3}+\underline{a}_{12} \dot{I}_{3}+\underline{a}_{13} \dot{I}_{4}+\underline{a}_{14} \dot{U}_{4}, \\
\dot{I}_{1}=\underline{a}_{21} \dot{U}_{3}+\underline{a}_{22} \dot{I}_{3}+\underline{a}_{23} \dot{I}_{4}+\underline{a}_{24} \dot{U}_{4}, \\
\dot{I}_{2}=\underline{a}_{31} \dot{U}_{3}+\underline{a}_{32} \dot{I}_{3}+\underline{a}_{33} \dot{I}_{4}+\underline{a}_{34} \dot{U}_{4}, \\
\dot{U}_{2}=\underline{a}_{41} \dot{U}_{3}+\underline{a}_{42} \dot{I}_{3}+\underline{a}_{43} \dot{I}_{4}+\underline{a}_{44} \dot{U}_{4} .
\end{array}\right.
$$

To simplify the form of formulas, complex amplitudes of voltages and currents, as well as complex passive elements, are conditionally designated in a simplified form. In accordance with the second Kirchhoff law, for a section of a rail line of $d x$ length, we have (Polyanin and Manzhirov, 2006):

$$
z_{1} d x \cdot i_{1}+u_{1}-\left(u_{1}+d u_{1}\right)=e_{M_{1}}
$$


given that $e_{M_{1}}=-z_{M} d x \cdot i_{2}$, and in accordance with Figure 1, we obtain a system of differential equations of the following form:

$$
\left\{\begin{array}{l}
\frac{d u_{1}}{d x}=z_{1} i_{1}+z_{M} i_{2}, \\
\frac{d i_{1}}{d x}=\left(g_{1}+g_{12}\right) u_{1}-g_{12} u_{2}, \\
\frac{d i_{2}}{d x}=-g_{12} u_{1}+\left(g_{2}+g_{12}\right) u_{2}, \\
\frac{d u_{2}}{d x}=z_{M} i_{1}+z_{2} i_{2} .
\end{array}\right.
$$

The solution of the system according to $\dot{U}_{1}(x)$ (Figure 1) in the normal mode is determined by the expression:

$$
u_{1}(x)=A_{1} \operatorname{ch} \gamma_{1} x+A_{2} \operatorname{sh} \gamma_{1} x+A_{3} \operatorname{ch} \gamma_{2} x+A_{4} \operatorname{sh} \gamma_{2} x
$$

where $\gamma_{1}=\sqrt{a_{2}-\sqrt{a_{2}^{2}-a_{0}}} ; \gamma_{2}=\sqrt{a_{2}+\sqrt{a_{2}^{2}-a_{0}}} ;$

$a_{0}=\left(z_{1} z_{2}-z_{M}^{2}\right)\left(g_{1} g_{2}+g_{1} g_{12}+g_{2} g_{12}\right)$

$a_{2}=\frac{1}{2}\left[g_{12}\left(z_{1}+z_{2}-2 z_{M}\right)+g_{1} z_{1}+g_{2} z_{2}\right]$.

$A_{1}, A_{2}, A_{3}, A_{4}$ - constant, arbitrarily dependent on the boundary conditions of the problem. The rates of the complex values of voltages and currents $\dot{U}_{1}(x), \dot{U}_{2}(x), \dot{I}_{1}(x), \dot{I}_{2}(x)$ for each correctly posed case can be expressed in terms of the values of constants $A_{1}, A_{2}, A_{3}, A_{4}$, some additional coefficients $\underline{h}_{1}, \underline{h}_{2}$, and a square matrix $\left[y_{i j}\right] \cdot i \in 1,2 ; j \in 1,2$ :

$$
\begin{gathered}
\underline{u}_{2}(x)=\underline{h}_{1}\left(\underline{A}_{1} \operatorname{ch} \underline{\gamma}_{1} x+\underline{A}_{2} \operatorname{sh} \underline{\gamma}_{1} x\right)+\underline{h}_{2}\left(\underline{A}_{3} \operatorname{ch} \underline{\gamma}_{2} x+\underline{A}_{4} \operatorname{sh} \underline{\gamma}_{2} x\right), \\
\underline{h_{1}}=\frac{\underline{\gamma}_{1}^{2}-\underline{z}_{1}\left(g_{1}+g_{12}\right)+\underline{z}_{M} g_{12}}{\underline{z}_{M}\left(g_{2}+g_{12}\right)-\underline{z}_{1} g_{12}} ; \\
\underline{h}_{2}=\frac{\underline{\gamma}_{2}^{2}-\underline{z}_{1}\left(g_{1}+g_{12}\right)+\underline{z}_{M} g_{12}}{\underline{z}_{M}\left(g_{2}+g_{12}\right)-\underline{z}_{1} g_{12}} ; \\
\underline{i}_{1}(x)=y_{11}\left(A_{1} \operatorname{sh} \gamma_{1} x+A_{2} \operatorname{ch} \gamma_{1} x\right)+y_{12}\left(A_{3} \operatorname{sh} \gamma_{2} x+A_{4} \operatorname{ch} \gamma_{2} x\right), \\
\underline{i}_{2}(x)=y_{21}\left(A_{1} \operatorname{sh} \gamma_{1} x+A_{2} \operatorname{ch} \gamma_{1} x\right)+y_{22}\left(A_{3} \operatorname{sh} \gamma_{2} x+A_{4} \operatorname{ch} \gamma_{2} x\right),
\end{gathered}
$$

where 
$\left[y_{i j}\right]=\frac{1}{z_{1} z_{2}-z_{M}^{2}}\left[\begin{array}{ll}\gamma_{1}\left(z_{2}-h_{1} z_{M}\right) & \gamma_{2}\left(z_{2}-h_{2} z_{M}\right) \\ \gamma_{1}\left(h_{1} z_{1}-z_{M}\right) & \gamma_{2}\left(h_{2} z_{1}-z_{M}\right)\end{array}\right]$.

Let's express the values of the complex amplitudes $\dot{U}_{1}, \dot{I}_{1}, \dot{U}_{2}, \dot{I}_{2}$ in terms of the RL parameters, and to do this, we differentiate $(x)$ both parts of the equation by the coordinate:

$$
\frac{d^{2} u_{1}}{d x^{2}}=z_{1} \frac{d i_{1}}{d x}+z_{M} \frac{d i_{2}}{d x}
$$

Then let's transform the right side of equation (5):

$$
\begin{aligned}
& \frac{d^{2} u_{1}}{d x^{2}}=z_{1}\left[\left(g_{1}+g_{12}\right) u_{1}-g_{12} u_{2}\right]+z_{M}\left[\left(g_{2}+g_{12}\right) u_{2}-g_{12} u_{1}\right]= \\
& \quad=u_{1}\left[z_{1}\left(g_{1}+g_{12}\right)-z_{M} g_{12}\right]+u_{2}\left[z_{M}\left(g_{2}+g_{12}\right)-z_{1} g_{12}\right] .
\end{aligned}
$$

In equation (6), we express the variable $u_{2}$ :

$$
u_{2}=\frac{1}{z_{M}\left(g_{2}+g_{12}\right)-z_{1} g_{12}}\left\{\frac{d^{2} u_{1}}{d x_{1}}-u_{1}\left[z_{1}\left(g_{1}+g_{12}\right)-z_{M} g_{12}\right]\right\} \text {. }
$$

Differentiating twice on $x$ and substituting in the right side of the equation for $\frac{d^{2} u_{1}}{d x^{2}}$ and $u_{1}$, we get:

$$
\begin{gathered}
u_{2}=\frac{1}{z_{M}\left(g_{2}+g_{12}\right)-z_{1} g_{12}}\left\{\gamma_{1}^{2} A_{1} \operatorname{ch} \gamma_{1} x+\gamma_{1}^{2} A_{2} \operatorname{sh} \gamma_{1} x+\gamma_{2}^{2} A_{3} \operatorname{ch} \gamma_{2} x+\gamma_{2}^{2} A_{4} \operatorname{sh} \gamma_{2} x-\right. \\
\left.-\left[A_{1} \operatorname{ch} \gamma_{1} x+A_{2} \operatorname{sh} \gamma_{1} x+A_{3} \operatorname{ch} \gamma_{2} x+A_{4} \operatorname{sh} \gamma_{2} x\right]\left[z_{1}\left(g_{1}+g_{12}\right)-z_{M} g_{12}\right]\right\}= \\
=\frac{\gamma_{1}^{2}+z_{M} g_{12}-z_{1}\left(g_{1}+g_{12}\right)}{z_{M}\left(g_{2}+g_{12}\right)-z_{1} g_{12}} \cdot A_{1} \operatorname{ch} \gamma_{1} x+\frac{\gamma_{1}^{2}+z_{M} g_{12}-z_{1}\left(g_{2}+g_{12}\right)}{z_{M}\left(g_{2}+g_{12}\right)-z_{1} g_{12}} \cdot A_{2} \operatorname{sh} \gamma_{1} x+ \\
+\frac{\gamma_{2}^{2}+z_{M} g_{12}-z_{1}\left(g_{1}+g_{12}\right)}{z_{M}\left(g_{2}+g_{12}\right)-z_{1} g_{12}} \cdot A_{3} \operatorname{ch} \gamma_{2} x+\frac{\gamma_{2}^{2}+z_{M} g_{12}-z_{1}\left(g_{1}+g_{12}\right)}{z_{M}\left(g_{2}+g_{12}\right)-z_{1} g_{12}} \cdot A_{4} \operatorname{sh} \gamma_{2} x= \\
=F\left(\gamma_{1}\right)\left(A_{1} \operatorname{ch} \gamma_{1} x+A_{2} \operatorname{sh} \gamma_{1} x\right)+F\left(\gamma_{2}\right)\left(A_{3} \operatorname{ch} \gamma_{2} x+A_{4} \operatorname{sh} \gamma_{2} x\right),
\end{gathered}
$$

where $F(\gamma)=\frac{\gamma^{2}+z_{M} g_{12}-z_{1}\left(g_{1}+g_{12}\right)}{z_{M}\left(g_{2}+g_{12}\right)-z_{1} g_{12}}$.

We find expressions for the currents $i_{1}$ and $i_{2}$ and differentiate (1) by $x$. For convenience, we denote:

$$
\begin{gathered}
\theta_{1}=\frac{d u_{1}}{d x}=\gamma_{1} A_{1} \operatorname{sh} \gamma_{1} x+\gamma_{1} A_{2} \operatorname{ch} \gamma_{1} x+\gamma_{2} A_{3} \operatorname{sh} \gamma_{2} x+\gamma_{2} A_{4} \operatorname{ch} \gamma_{1} x, \\
\theta_{1}=\frac{d u_{2}}{d x}=h_{1} \gamma_{1} A_{1} \operatorname{sh} \gamma_{1} x+h_{1} \gamma_{1} A_{2} \operatorname{ch} \gamma_{1} x+h_{2} \gamma_{2} A_{3} \operatorname{sh} \gamma_{2} x+h_{2} \gamma_{2} A_{4} \operatorname{ch} \gamma_{1} x,
\end{gathered}
$$

where 


$$
\begin{aligned}
& h_{1}=F\left(\gamma_{1}\right)=\frac{\gamma_{1}^{2}+z_{M} g_{12}-z_{1}\left(g_{1}+g_{12}\right)}{z_{M}\left(g_{2}+g_{12}\right)-z_{1} g_{12}} ; \\
& h_{2}=F\left(\gamma_{2}\right)=\frac{\gamma_{2}^{2}+z_{M} g_{12}-z_{1}\left(g_{1}+g_{12}\right)}{z_{M}\left(g_{2}+g_{12}\right)-z_{1} g_{12}} .
\end{aligned}
$$

As a result, we get a second-order system of linear equations, relative to the desired $i_{1}$ and $i_{2}$ :

$$
\left\{\begin{array}{l}
z_{1} i_{1}+z_{M} i_{2}=B_{1} ; \\
z_{M} i_{1}+z_{2} i_{2}=B_{2} .
\end{array}\right.
$$

Having solved the system, we have:

$$
\begin{gathered}
i_{1}=\frac{B_{1} z_{2}-B_{2} z_{M}}{z_{1} z_{2}-z_{M}^{2}}=\frac{z_{2} \gamma_{1}-z_{M} h_{1} \gamma_{1}}{z_{1} z_{2}-z_{M}^{2}}\left(A_{1} \operatorname{sh} \gamma_{1} x+A_{2} \operatorname{ch} \gamma_{1} x\right)+ \\
+\frac{z_{1} \gamma_{2}-z_{M} h_{2} \gamma_{2}}{z_{1} z_{2}-z_{M}^{2}}\left(A_{3} \operatorname{sh} \gamma_{2} x+A_{4} \operatorname{ch} \gamma_{2} x\right)= \\
=y_{11}\left(A_{1} \operatorname{sh} \gamma_{1} x+A_{2} \operatorname{ch} \gamma_{1} x\right)+y_{12}\left(A_{3} \operatorname{sh} \gamma_{2} x+A_{4} \operatorname{ch} \gamma_{2} x\right),
\end{gathered}
$$

where $\quad y_{11}=y_{1} \frac{z_{2}-h_{1} z_{M}}{z_{1} z_{2}-z_{M}^{2}} ; y_{12}=y_{2} \frac{z_{2}-h_{2} z_{M}}{z_{1} z_{2}-z_{M}^{2}}$

$$
\begin{gathered}
i_{2}=\frac{z_{1}}{z_{1} z_{2}-z_{M}^{2}}=\gamma_{1} \frac{z_{1} h_{1}-z_{M}}{z_{1} z_{2}-z_{M}^{2}}\left(A_{1} \operatorname{sh} \gamma_{1} x+A_{2} \operatorname{ch} \gamma_{1} x\right)+ \\
+\gamma_{2} \frac{h_{2} z_{1}-z_{M}}{z_{1} z_{2}-z_{M}^{2}}\left(A_{3} \operatorname{sh} \gamma_{2} x+A_{4} \operatorname{ch} \gamma_{2} x\right)= \\
=y_{21}\left(A_{1} \operatorname{sh} \gamma_{1} x+A_{2} \operatorname{ch} \gamma_{1} x\right)+y_{22}\left(A_{3} \operatorname{sh} \gamma_{2} x+A_{4} \operatorname{ch} \gamma_{2} x\right),
\end{gathered}
$$

where $y_{21}=y_{1} \frac{z_{1} h_{1}-z_{M}}{z_{1} z_{2}-z_{M}^{2}} ; y_{22}=y_{2} \frac{h_{2} z_{1}-z_{M}}{z_{1} z_{2}-z_{M}^{2}}$.

As a result, we get a system of equations using the notations of complex amplitudes of currents and voltages according to Figure 2:

$$
\left\{\begin{array}{l}
\dot{U}_{3}=A_{1}+A_{3}, \\
\dot{U}_{4}=h_{1} A_{1}+h_{2} A_{3}, \\
\dot{I}_{3}=y_{11} A_{2}+y_{12} A_{4}, \\
\dot{I}_{4}=y_{21} A_{2}+y_{22} A_{4} .
\end{array}\right.
$$

Let's specify the parameters $A_{1}, A_{2}, A_{3}, A_{4}$ in terms of complex amplitudes $\dot{U}_{3}, \dot{U}_{4}, \dot{I}_{3}, \dot{I}_{4}$ :

$$
\begin{aligned}
& A_{1}=\frac{\dot{U}_{3} h_{2}-\dot{U}_{4}}{h_{2}-h_{1}} ; A_{2}=\frac{\dot{I}_{3} y_{22}-\dot{I}_{4} y_{12}}{d} ; \\
& A_{3}=\frac{\dot{U}_{4}-\dot{U}_{3} h_{1}}{h_{2}-h_{1}} ; A_{4}=\frac{\dot{I}_{4} y_{11}-\dot{I}_{3} y_{21}}{d} .
\end{aligned}
$$




$$
d=y_{11} y_{22}-y_{21} y_{12} \text {. }
$$

In expressions (1-4), we assume that the coordinate $x=l,(l$ is the length of the line $)$, then:

$$
\left\{\begin{array}{l}
\dot{I}_{1}=y_{11} S_{1} A_{1}+y_{11} C_{1} A_{2}+y_{12} S_{2} A_{3}+y_{12} C_{2} A_{4}, \\
\dot{I}_{2}=y_{21} S_{1} A_{1}+y_{21} C_{1} A_{2}+y_{22} S_{2} A_{3}+y_{22} C_{2} A_{4}, \\
\dot{U}_{1}=C_{1} A_{1}+S_{1} A_{2}+C_{2} A_{3}+S_{2} A_{4}, \\
\dot{U}_{2}=h_{1} C_{1} A_{1}+h_{1} S_{1} A_{2}+h_{2} C_{2} A_{3}+h_{2} S_{2} A_{4},
\end{array}\right.
$$

where $S_{1}=\operatorname{sh} \gamma_{1} l ; C_{1}=\operatorname{ch} \gamma_{1} l ; S_{2}=\operatorname{sh} \gamma_{2} l ; C_{2}=\operatorname{ch} \gamma_{2} l$.

Setting $A_{1}, A_{2}, A_{3}, A_{4}$, according to (7) in the right part of equations (8), and grouping by $\dot{U}_{3}, \dot{U}_{4}, \dot{I}_{3}, \dot{I}_{4}$, we get the desired matrix $A-$ a three-wire electric line.

$$
[\mathrm{A}]=\left|\begin{array}{cccc}
\frac{h_{2} C_{1}-h_{1} C_{2}}{h_{2}-h_{1}} & \frac{y_{22} S_{1}-y_{21} S_{2}}{d} & \frac{y_{11} S_{2}-y_{12} S_{1}}{d} & \frac{C_{2}-C_{1}}{h_{2}-h_{1}} \\
\frac{h_{2} y_{11} S_{1}-h_{1} y_{12} S_{2}}{h_{2}-h_{1}} & \frac{y_{11} y_{22} C_{1}-y_{12} y_{21} C_{2}}{d} & \frac{y_{11} y_{12}\left(C_{2}-C_{1}\right)}{d} & \frac{y_{12} S_{2}-y_{11} S_{1}}{h_{2}-h_{1}} \\
\frac{h_{2} y_{21} S_{1}-h_{1} y_{22} S_{2}}{h_{2}-h_{1}} & \frac{y_{21} y_{22}\left(C_{1}-C_{2}\right)}{d} & \frac{y_{11} y_{22} C_{1}-y_{12} y_{21} C_{2}}{d} & \frac{y_{22} S_{2}-y_{21} S_{1}}{h_{2}-h_{1}} \\
\frac{h_{2} h_{1}\left(C_{1}-C_{2}\right)}{h_{2}-h_{1}} & \frac{h_{1} y_{22} S_{1}-h_{2} y_{21} S_{2}}{d} & \frac{h_{2} y_{11} S_{2}-h_{1} y_{12} S_{1}}{d} & \frac{h_{2} C_{2}-h_{1} C_{1}}{h_{2}-h_{1}}
\end{array}\right|
$$

\section{RESULTS}

To study the trajectory of changes in the complex amplitudes of voltages and currents at the RL output, the authors developed a machine program for analyzing track circuits ARC-1, and using the developed matrix [A] of parameters of the RL multi-pole in the normal mode class (9), simulation modeling was performed and the simulation results were presented as a hodograph of the complex voltage amplitude at the output of the rail multi-pole in Figure 3. 


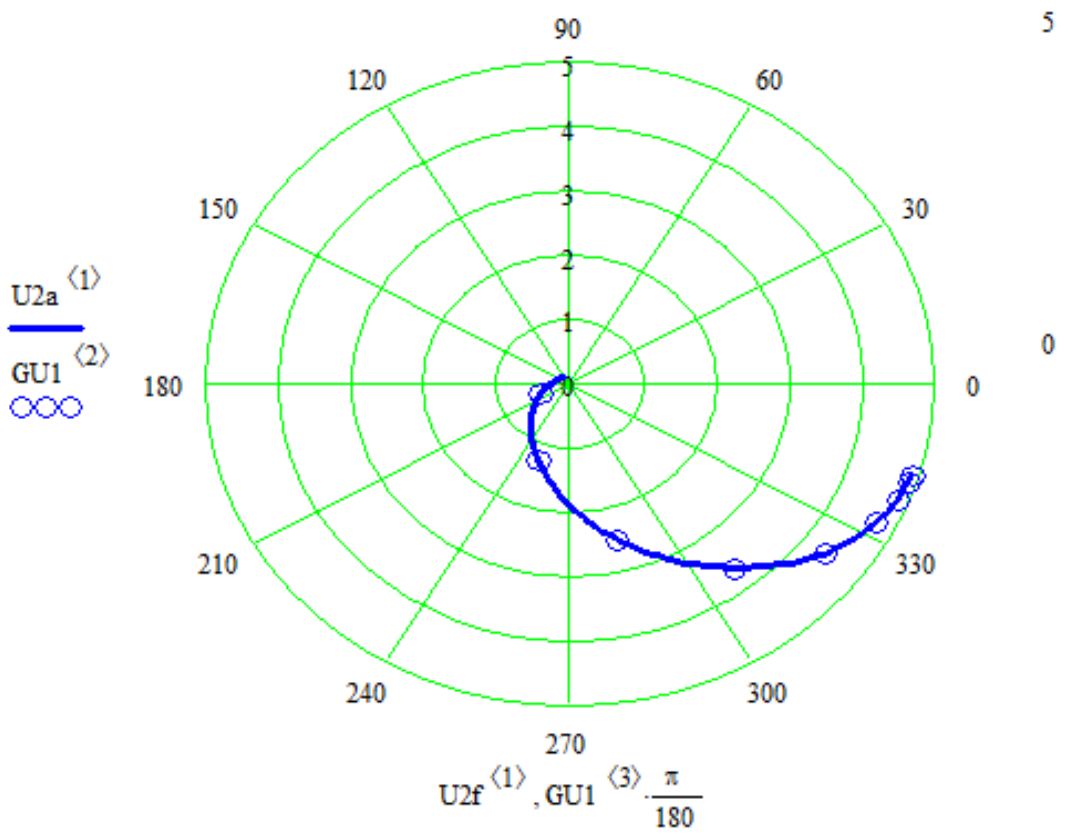

Figure 3. Hodograph of the complex amplitude of the output voltage of the rail line in the simulation of the normal mode.

When modeling the asymmetric mode with the simulation of the asymmetry of one rail connected to the contact-line supports, using the matrix A-parameters of the rail line obtained by the developed method, the possibility of analyzing the asymmetric states of the rail lines was confirmed. Thus, in the range of change in the conductivity of the supports from 0.02 to $2 \mathrm{~cm} / \mathrm{km}$, the dynamic range of voltage change is $\mathrm{K}_{\mathrm{d}}=1.21$, and this phenomenon cannot be taken into account when modeling a four-pole equivalent circuit of a rail line.

\section{CONCLUSION}

The multifactorial nature of the states space of a rail line, caused by a variety of classes of states, as well as the impact of destabilizing factors that lead to the appearance of transverse and longitudinal asymmetry and a significant range of change in perturbing influences, forms the task of developing new models of the rail lines states. One of the approaches to solving the problem is to consider a rail line, which is a line with distributed parameters, as a multi-pole. The developed generalized mathematical models are represented by a cascade connection of the matrices $[\mathrm{A}]$ of the parameters of the track circuit elements $\left(\mathrm{USZ}_{\mathrm{n}}-\mathrm{DT}_{\mathrm{n}}-\mathrm{RL}-\right.$ $\mathrm{DT}_{\mathrm{k}}-\mathrm{USZ}_{\mathrm{k}}$ ), represented by multi-poles. Such representation of the structure of the track circuit allows to flexibly change the substitution scheme depending on the RL configuration and to conduct a study of the space of states of any track circuits types. The results of the simulation modeling allow us to conclude that the multi-pole representation of the components of the track circuit schemes takes into account the violation of the equipotentiality of the scheme and allows to study the flow of currents through bypass circuits and the earth path.

\section{REFERENCES}

Bruin, T., Verbert, K. and Babuska, R. (2017). Railway track circuit fault diagnosis using recurrent neural networks. IEEE Transactions on Neural Networks and Learning Systems, 28 (3), 523-533. 
Gao, H. and Ma, H. (2021). Influence of circuit signal integrity on electromagnetic compatibility and countermeasures. In: L. Wang (Ed.), Global Intelligent Industry Conference, SPIE Proceedings (vol. 11780, 1178025). Bellingham, WA: SPIE.

Kravtsov, Yu. A. (2015). Electromagnetic compatibility of track circuits and electric stock with asynchronous traction drive. Automation on Transport, 1, 47-56.

Polyanin, A. and Manzhirov, A. (2006). Handbook of mathematics for engineers and scientists. London, UK: Chapman and Hall/CRC Press.

Shamanov, V. I. (2013). Electromagnetic compatibility of railway automatics and telemechanics systems. Moscow, Russia: EMC for Education on Railway Transport.

Tarasov, E. M. (2017). On ensuring invariance in problems of control of rail-line conduction. Russian Electrical Engineering, 88 (3), 105-108.

Tarasov, E. M., Andronchev, I. K., Bulatov, A. A. and Tarasova, A. E. (2020). Development of a trainable classifier of state of rail lines with multiple patterns of image recognition. Engineering Technologies and Systems, 30 (4), 659-682.

Volkov, E. A., Sankovskij, Je. I. and Sidorovich, D. Yu. (2005). Theory of linear electric circuits of railway automatics, telemechanics and communications. Moscow, Russia: Marshrut. 